\title{
Telecollaborative Foreign Language Networks in European Universities: A Report on Current Attitudes and Practices
}

\author{
Sarah Guth, Francesca Helm \& Robert O'Dowd \\ University of Padova, Italy \& University of León, Spain
}

Article received 29 October 2014, accepted 5 November 2014, final version received 15 December 2014

\begin{abstract}
This paper reports on a survey which sought to identify the state of the art in the practice of telecollaboration in Europe. It was the first large scale survey carried out on the practice of telecollaboration in Europe and was carried out as part of the European Commission funded project, INTENT - Integrating Telecollaborative Networks into Foreign Language Higher Education. Also known as Online Intercultural Exchange (OIE), telecollaboration engages groups of foreign language learners in virtual intercultural interaction and exchange with partner classes in geographically distant locations. Much research has been carried out on telecollaboration, though this comprises largely of small-scale studies on single telecollaboration projects. The aim of this paper is to discuss the findings from the final report on the survey, provide recommendations for decision-makers and teachers based on these findings and present the UniCollaboration website that was developed largely on the basis of the findings. The paper ends with a brief comparison of the INTENT survey results to findings from two other OIE projects: eTwinning and the COIL Institute for Globally Networked Learning in the Humanities.
\end{abstract}

\section{Introduction}

Foreign language telecollaboration or Online Intercultural Exchange (OIE) ${ }^{1}$ engages groups of foreign language learners in virtual intercultural interaction and exchange with partner classes in geographically distant locations. Despite its relatively short history, OIE has established itself as a rich sub-field of Computer Assisted Language Learning (CALL) and Computer-Mediated Communication (CMC), with hundreds of journal articles on the theme, dedicated volumes (Belz \& Thorne, 2006; Dooly, 2008; Guth \& Helm, 2010; Kern \& Warschauer, 2000; O'Dowd, 2007), journal special editions (Belz, 2003; Lewis, Chanier, \& Youngs, 2011) and a book series, Telecollaboration in Education, edited by O'Dowd and Dooly. Telecollaboration research has progressed from collections of classroom practice and anecdotal research to in-depth studies of online interaction and exchange (Dooly \& O'Dowd, 2012). The research has also documented failure and difficulties, which have been attributed to a wide range of factors (O'Dowd \& Ritter, 2006; Lamy \& Goodfellow, 2010). Whether based on psycholinguistic SLA paradigms or a more sociocultural approach, the literature has mostly produced in-depth studies of individual projects and contexts, focusing on pedagogic design, the technologies used, analyses of student interaction, linguistic and/or intercultural learning outcomes, difficulties and barriers. There have, however, until very recently, been no large-scale surveys on the practice of telecollaboration in the 
foreign language class in tertiary education. Indeed, the literature shows that this practice has tended to be bottom up, meaning that projects have predominantly grown out of the individual initiative of single teachers and practitioners rather than as a response to top-down requirements established by university departments and faculties. The INTENT survey, which is reported in this paper, sought to verify this fact and address this gap in the literature, at least in part, by seeking to map telecollaboration practice in higher education institutions (HEIs) across a broad geographic area, Europe.

A preliminary study carried out by O'Dowd (2011), revealed that telecollaboration was very much a peripheral add-on activity in foreign language classes. The study found that "telecollaboration remains the reserve of highly motivated pioneer teachers who are particularly convinced of the benefits of this activity and who are probably engaged in research related to its outcomes" (O’Dowd, 2011, p. 10). The initial findings of this survey reported "a rather bleak picture" (Ibid.) as regards the integration of telecollaboration in higher education foreign language programmes. The main challenges identified were a lack of stability in project partners, limited interest of colleagues, and problems integrating online exchanges into course syllabi and course evaluation.

In October 2011 the INTENT group (Integrating Telecollaborative Networks into Foreign Language Higher Education) was awarded funding by the European Commission's Lifelong Learning programme to carry out a 30-month project ${ }^{2}$. The aim of the project was to raise awareness among students, educators, student mobility coordinators and (senior) managers at university level of the advantages of telecollaboration as a tool for virtual mobility in foreign language higher education, where the focus has been very much on physical mobility. The project also aimed to achieve more effective integration of telecollaboration in university institutions in general by providing tools and resources to support foreign language educators with its implementation.

The INTENT project started with a survey to gain a representative overview of telecollaborative practice amongst European universities. Although the survey offered insight into the state of the art of telecollaboration practice in 2011, the INTENT team tried to complete this assessment with eight case studies of successfully implemented OIE projects in European HEIs (Guth, Helm \& O'Dowd, 2012). This paper reports on the primary findings of the survey and the case studies and offers recommendations based on these findings as well as those from OIE projects in secondary schools (eTwinning) and outside of the realm of foreign language learning (COIL). 


\section{University Language Classes Collaborating Online: Report on the Integration of Telecollaborative Networks in European Universities}

The INTENT survey sought to identify the characteristics of telecollaborative practices currently undertaken by European university educators and explore the barriers practitioners encounter when organising online intercultural exchanges. The project team was also interested in the student perspective so the views and opinions of European students with different OIE experiences, with regard to the impact that participating in online exchange has had on them, were also gathered in the survey. Complete responses were obtained from 210 university educators in 23 European countries and 131 students who had engaged in a telecollaboration project.

In the second part of the study, the project team collected case studies of universities, partnerships and telecollaborative networks which could provide a representative, qualitative picture of the type of online intercultural exchanges which are being carried out around Europe and which have achieved a certain level of integration in their institutions' study programmes. The case studies involved exchanges taking place between universities in Ireland and Germany, Italy and the UK, Sweden and the USA, and Latvia and France, among others. The collection also included an example of a telecollaborative network of various exchange partners working together as well as the description of an Italian university which had staff involved in multiple projects.

\section{Principal Findings of the Study}

The combination of the teacher and student surveys with the collection of case studies enabled the project team to shed light on the state of telecollaborative practices in European Institutions of Higher Education. These findings are outlined here briefly.

The survey provided some interesting insights into the national and linguistic profiles of the exchanges currently being carried out in European universities. It became clear from the survey, for example, that the majority of exchanges involved the use of English as a foreign language. However, a considerable number of teachers of French, German and Spanish also responded as well as teachers of less commonly taught languages. This demonstrates that OIE is an activity which can be of value to teachers and students of any language. Interestingly, most of the OIEs reported involved classes from European universities collaborating with partner classes with US universities. There were few exchanges between universities in European countries and there were also few connecting Europe and the so-called 'developing world' or emerging countries/economies. This may be attributed both to the predominance of English as a foreign language in the survey as well as 
an established belief amongst many practitioners that students benefit more from interacting with 'native speakers' than with other learners of the foreign language (FL) they are studying. However, the practice of partnering two groups of students studying the same FL is becoming more common as is bringing together groups of FL learners with groups of teacher trainees of that FL (Guth \& Helm, 2010), especially since these arrangements allow FL students to spend all their time using the FL rather than half their time using their own native language and the other half the FL according to philosophy of reciprocity of the tandem model.

It was seen that most practitioners give priority in their exchanges to the development of students' intercultural competence and foreign language skills, but developing students' online literacies and learner autonomy were also mentioned regularly as well. Practitioners strongly believe that OIEs have the potential of supporting physical mobility by engaging learners with students in their future host institution before departure, and also by supporting learners during their period abroad. However, there were very few examples of such exchanges being carried out.

Interestingly, the survey revealed that foreign language educators rarely find telecollaborative partners through institutional partnerships such as Erasmus. Instead, most establish exchanges with colleagues from their own academic networks or from contacts made at conferences. In general, OIEs are carried out by highly motivated educators who believe strongly in the outcomes of these exchanges. They have often had experience of OIE as part of their training, had colleagues who speak positively of the experience and, as the practice becomes more common, may also see the potential of carrying out research in OIE. Although educators who have had experience of OIE are likely to repeat the experience, lack of time and organizational difficulties are seen to be the main factors hindering the take up of these projects by other educators. Indeed, the model of OIE "seemed so unique, so free-standing and so outside of a traditional university niche, that other academics saw the model as at once challenging and unintentionally 'owned' by the innovating teacher" (Rubin \& Guth in press). Furthermore, the lack of institutional recognition and support was also a factor.

Technology, of course, plays a role in OIE. According to the survey, the most frequently used tools in Europe were email and virtual learning environments. However, due to the spread of broadband and user-friendly Web 2.0 tools such as Skype and Facebook, there was also a considerably high use of audio/video conferencing which until recently was not so widely available. The main difficulty reported in using these real-time tools was organizational due to the difficulties in working with partners in very different time zones. 
The case studies revealed how telecollaboration can have different levels of integration into study programmes. While most practitioners assess the intercultural and communicative learning outcomes of their exchanges, participation in OIEs does not always offer students academic credit and their work is often not institutionally recognised. The more these exchanges are 'recognised' and awarded academic credit, the more likely they are to be considered of value by students and faculty members. While telecollaborative exchanges are recognised by many universities as valuable activities for internationalisation and for the development of student mobility, institutions are often unaware of the extra time and workload such projects require and are either unwilling or unable to provide adequate support to staff who want to organise such exchanges.

As regards the students' perspective, the impact of participating in OIEs is seen by students who have participated in projects to be educationally significant. Many reported that participating in a telecollaborative exchange led them to become more open to others, accepting and understanding of difference and to realise that their own points of view are not necessarily 'the best or only ones'. Many students reported establishing long term friendships with their telecollaboration peers, keeping in touch once exchanges are over and some even visiting one another. This would seem to indicate that where possible, OIEs are an incentive for students to engage in mobility be it through institutional programs or not.

\section{Strategies for Integrating Telecollaboration in University Institutions}

The report identified different strategies which have been used by practitioners around Europe to integrate telecollaborative projects more seamlessly into their institutions and classes. These included, for example, maintaining the same exchange partners over long periods and receiving the support of department heads in order to ensure that exchanges continue even when particular staff members change institutions.

Other strategies include having an agreement or memorandum of understanding (MOU) signed between practitioners in order to provide partners with a sense of security when planning exchanges and drawing up course guides for the coming academic year. Maintaining regular contact between educators is another key to success. In order for exchanges to be successful, it was seen that teachers need to be motivated, to believe in the value of the exchange and be willing to engage in regular virtual contact with their partner teacher before, during and after the actual period of class collaboration. Undoubtedly ensuring that students receive credit for these courses would be an additional motivator for students, but there were few examples of this in the findings. Finally, another significant strategy for integrating OIEs is to achieve prestige and importance for the 
projects by winning academic awards and holding press launches to announce the exchanges to the general public.

\section{Recommendations based on the study}

Based on the findings of the report, the INTENT project team made the following recommendations to decision makers working in Higher Education Institutions around Europe and to those working in the areas of education and student mobility in the institutions of the European Union.

\section{Recommendations for University Senior management}

- Exploit existing inter-institutional partnerships. Not only can these existing partnerships be a way for interested practitioners and departments to locate partner classes, but by making use of staff mobility, educators could visit each others' institutions and establish personal connections with colleagues. This type of face-to-face contact allows the partner teachers to better understand each others' contexts and collaborate in planning the exchanges, thus overcoming some of the challenges that online exchange involves.

- Draw up MOUs specifically for virtual mobility programmes. Although such agreements might not initially be legally binding, they would require partners, intended as educators and/or their institutions to make a commitment to the project. Model agreements could initially allow for staff mobility in order to set up the exchange and/or for educators to also teach the different groups of students. Subsequently these could be expanded to include new physical mobility agreements.

- Develop OIEs to support pre- and post-mobility programmes. With the training and support of international office and language centre staff exchanges, these 'pre-mobility exchanges' could improve the quality of physical mobility by promoting the integration of Erasmus students in host universities. Particularly when periods of mobility are short-term, OIEs can be used to continue communication and/or collaborative projects that students have begun to engage in during the period of mobility.

- Integrate OIE into teacher education programs. Integration implies both teaching about OIE as well as engaging teacher trainees in actual OIE projects. This would encourage future educators to integrate telecollaboration into their practice. It is also vital to provide incentives and support for educators embarking on their first experience of OIE. 
- Provide technical and administrative support. One of the main reasons for the lack of continuity of many OIEs is that they are developed from the bottom up by motivated teachers who receive little to no support. Over time even the most motivated educators give up when they are on their own. Therefore, a technical and administrative infrastructure that supports educators in their telecollaborative activity would lead to greater continuity of OIEs over time as well as encourage teachers who have not previously engaged in OIE projects to take their first steps.

- Recognize OIE as a valuable experience for all students. Telecollaboration should not be seen as an activity only for 'pure' foreign language students but also as a valid activity for students majoring in any subject. As was stated earlier from the findings of the study, the main goal cited by educators who have engaged in OIE is increasing students' intercultural communicative competence. Knowing how to interact, communicate with and work with people from different lingua-cultural backgrounds is important for all students.

\section{Recommendations for European Decision makers}

- Focus on the 80-90\%. The majority of university students in the EU do not participate in learning mobility and should be considered by supporting the mainstreaming of online intercultural exchange between students at European Universities.

- Establish European grants for virtual mobility. Although OIE is undoubtedly less expensive than physical mobility there are still organizational costs that need to be considered. If telecollaboration is to become an established practice in European universities, it is necessary to invest in staff and infrastructure as well as incentives for educators to set up OIEs and, where possible, travel to one another's institutions. A small contribution from the EU towards these costs, in the form of a virtual mobility grant, would assist universities in promoting virtual mobility.

- Award credits for participation in OIEs. Decision makers should find systems of awarding academic credits (ECTS) for students' participation in OIEs. Alternative ways of awarding credit, such as explicit mention of the activity in the European Diploma Supplement, should also be supported. 


\section{Recommendations for Foreign Language Teachers}

The results of the survey also allowed the INTENT team to draw up several recommendations for foreign language teachers interested in setting up OIE projects. In terms of partnerships, teachers are advised to work with a distant colleague they already know and feel comfortable with. If this is not possible, partner-finding sites such as the UNICollaboration platform (see below) can be used, but it is important to get to know potential partners before and whilst setting up an exchange. Having a good working relationship with a partner is fundamental for the success of a project.

For educators who are beginning with telecollaboration, it is advisable to start with a manageable project and just one partner. Different types of partnerships are possible, for instance between students of different disciplines, or students and teacher trainees. Different language configurations are also feasible, such as 'lingua franca' exchanges where none of the participants are 'native speakers' of the language being used, or plurilingual exchanges. As you gain experience you can begin to design more complex projects, possibly with more than one partner.

It is important to establish procedures and expectations at the outset, if possible laying them out in a document which all partners undersign. When and how will you communicate as teachers? And your students? What are your objectives and how will you achieve them? What resources and tasks will you use? How will you resolve problems? What kind of technical support will be available at both institutions? Whilst it is possible, and indeed likely, that some objectives may be different for the groups involved, it is important that partners know one another's objectives and that they decide on tasks which will be engaged in by all of the students, but which can be integrated and adjusted to meet local needs at all sides.

Students also need to be prepared for the exchange. They should be informed about the project's aims and objectives, the type of interaction they may expect, assessment modes and criteria. Their expectations should be discussed and they should be prepared for online communication and the challenges they may face.

A consequence of the authenticity of telecollaboration is that the progress of the exchange and student interactions cannot be predicted. It is thus important for teachers to be flexible and prepared for the unexpected, able to step away from lesson plans and be ready to adopt alternative plans in case of technical problems and/or lack of contact from partners.

In terms of technology, there are so many possibilities available to teachers that it may be difficult to choose. What is important to bear in mind is that different tools are more or less suited for different purposes and the different skills students may need to develop. Technology is not the starting point of project design, but should be chosen according to the pedagogic aims and planned 
tasks and activities. Choices will then need to be made regarding the use of proprietary software and learning management systems if they are going to be used, for instance whose platform is going to be used? Who will register the students? If proprietary software is used who meets the cost? How long will the exchanges and material be available to students and teachers? If teachers decide to use more open systems, such as Web 2.0 tools and social networks, they need to take into consideration issues such as privacy and copyright, and make students aware of these. Teachers will also need to feel comfortable with the tools they are using.

Finally, an important issue for teachers to consider is assessment and recognition of the activity they are involving students in. This is important because it can have an impact on students' participation and commitment to the project and thus can also compromise the success of the exchange. There are many different ways of assessing students' work in telecollaboration projects, from what we found to be the most commonly used approaches such as reflective essays, diaries to the use of electronic portfolios. Portfolio assessment allows students to 'collect evidence' of their progress, to reflect on their evolution and evaluate improvement.

\section{Survey Follow-Up}

The survey results provided valuable input for the tools and training materials that the INTENT team subsequently developed for the project. The UNICollaboration platform (www.unicollaboration.eu) (see Figure 1) serves as the hub for these resources, offering partnerclass finding functions, resources that can be used in telecollaboration projects, training materials to prepare educators for telecollaboration, sample projects which offer ideas on the type of exchange educators can plan and a community of educators with experience of or a strong interest in telecollaboration. To date, the platform has over 650 registered users. 


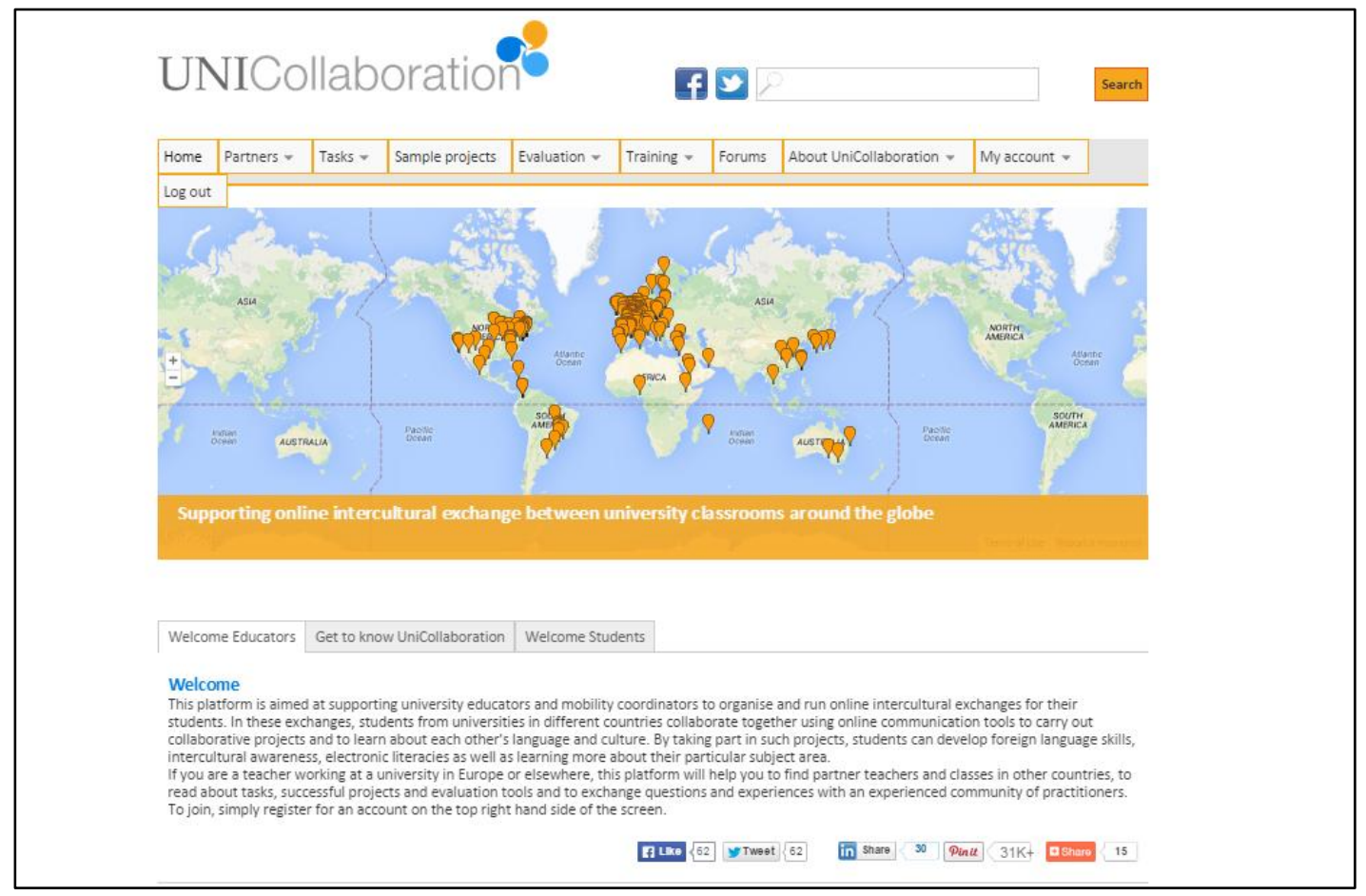

Figure 1: The UNICollaboration platform

The UNICollaboration platform also offers training materials and advice for teachers wishing to engage in telecollaboration. Teachers can watch video recordings of experienced telecollaboration practitioners and researchers and read short articles and frequently asked questions regarding telecollaboration. Registered users can participate in the forum discussions amongst the telecollaboration community.

\section{OIE in Other Contexts}

The practice of telecollaboration in European higher education lacks institutional support and recognition as a pedagogic approach, but the situation in schools is quite different. The European Commission funded initiative, eTwinning, encourages the use of information and communication technology (ICT) to promote cooperation between schools, to facilitate and promote the development of joint projects using the tools and Internet spaces made available through the European eTwinning portal. The eTwinning project has over 130,000 registered schools on its portal, and has been successful in terms of creating collaboration between teachers across Europe, but according to a recent impact study, interaction is primarily between students:

direct interaction with pupils in partner schools is still not frequent. Synchronous work by pupils in different countries appears to be unusual, constrained often by timetabling, time differences and lack of appropriately robust ICT infrastructure, and in most of the case study 
schools, email was the only form of online communication between pupils. (Education for Change 2013, p. 7)

Whilst interaction between students is a sine qua non of telecollaboration, this does not seem to be the case in eTwinning.

Though eTwinning regards primary schools, the impact report raises many of the issues which are addressed in the INTENT survey study concerning Higher Education. eTwinning is not specifically targeted for language learning, yet the largest group of the 6000 respondents to the eTwinning survey (Education for Change, 2013) were language teachers (46\%). The aim of the eTwinning impact study was to assess impact in terms of pedagogy, teacher professional development and pupil learning, looking at the factors that contribute to or constrain teachers' participation in eTwinning. The report describes several perceived advantages of eTwinning for teachers, such as networking across Europe, acquiring new or improved ICT skills and pedagogical innovation, particularly through the introduction of team work and project-based approaches. Yet the report also noted that teachers rarely receive any official recognition from their education authorities or change in status as a result of their eTwinning work. The situation is not so different in higher education, as the INTENT study has found.

In the US, a model similar to telecollaboration, called Collaborative Online International Learning (COIL), has taken hold. Like eTwinning, COIL is not aimed specifically at foreign language teachers and learners, but like telecollaboration or OIE, the focus is on direct interaction and collaboration between students. The name COIL was coined at the State University of New York (SUNY) where a Center for COIL was established in 2006 with the aim to promote the development of COIL projects across the 64 campuses that make up the SUNY system. In 2010 the COIL Center was awarded a grant by the US National Endowment for the Arts to create the COIL Institute for Globally Networked Learning in the Humanities (http://coil.suny.edu/page/about-coilinstitute-globally-networked-learning-humanities). The Institute ran from 2011 to 2013 and supported the development and implementation of 24 COIL/OIE projects. At the end of the Institute, partners were asked to complete a relatively detailed case study; a final report analyzing the data from the case studies was published online as a white paper (Guth, 2013). It is interesting to note that the results of this report are extremely similar to those from the INTENT report even if they focused on US institutions and universities around the world from Kenya, to Japan, to the Galapagos Islands. Despite the fact that institutional support was a requirement for participating in the Institute, the majority of partners reported receiving little to no support (financial, administrative, technical or pedagogical). This fact together with limited recognition (economic or 
otherwise), were cited as the main reasons why partners might not carry out further iterations of the project. Without going into further detail (see http://coil.suny.edu/sites/default/files/ case study report.pdf to view the report), the findings from both the INTENT and COIL reports highlight similar challenges to the normalization of online intercultural exchange regardless of the geographical location of the institution.

\section{Conclusion}

The findings of the INTENT report demonstrated that while the activity of OIE is proving increasingly popular and is being used and integrated in a myriad of ways around European universities, its long-term success depends on its wider recognition and greater integration in European university education as a whole. The report also identified a need for increased information and support for educators who may be potentially interested in taking up the activity. The reports on the eTwinning project and the COIL Institute for Globally Networked Learning in the Humanities confirmed that these findings are relevant at the secondary school level and across the globe where OIE is implemented. Based on the findings of the report, the INTENT team developed the UniCollaboration website, which contains numerous tools to support educators in achieving these aims of recognition, integration and dissemination of telecollaborative activity in European universities. Although the funding period for the INTENT project has ended, the UniCollaboration site continues and will continue to be an active online environment where educators (both foreign language and not), staff and administrators can come together in order to learn more about and discuss telecollaboration through the resources offered on the site.

\section{References}

Belz, J. A. (2003). From the special editor. Language Learning \& Technology, 7(2), 2-5.

Belz, J. A., \& Thorne, S. L. (2006). Internet-mediated intercultural foreign language education. Boston (MA): Thomson Heinle.

Dooly, M. (2008). Telecollaborative language learning. Bern: Peter Lang.

Dooly, M., \& O'Dowd, R. (Eds.). (2012). Researching online foreign language interaction and exchange: Theories, methods and challenges. Bern: Peter Lang.

Education for Change (2013). Study of the impact of eTwinning on participating pupils, teachers and schools. Luxembourg: European Union.

Guth, S., \& Helm, F. (Eds.). (2010). Telecollaboration 2.0. Language, literacies and intercultural learning in the 21st century. Bern: Peter Lang.

Guth, S., Helm F., \& O'Dowd, R. (2012). University language classes collaborating online. A report on the integration of telecollaborative networks in European universities. Retrieved from http://intent-project.eu/sites/default/files/Telecollaboration_report_Final_Oct2012.pdf 
Guth, S. (2013). The COIL Institute for Globally Networked Learning in the Humanities: Final Report. Retrieved from http://coil.suny.edu/sites/default/files/case_study_report.pdf

Kern, R., \& Warschauer, M. (2000). Network-based language teaching concepts and practice. Cambridge: Cambridge University Press.

Lamy, M., \& Goodfellow, R. (2010). Telecollaboration and learning 2.0. In S. Guth, \& F. Helm (Eds.), Telecollaboration 2.0. Language, literacies and intercultural learning in the 21 st century (pp. 107-138). Bern: Peter Lang.

Lewis, T., Chanier, T., \& Youngs, B. (2011). Special issue commentary: Multilateral online exchanges for language and culture learning. Language Learning \& Technology, 15(1), 3-9.

O'Dowd, R. (2007). Online intercultural exchange. Clevedon Buffalo Toronto: Multilingual Matters.

O'Dowd, R., \& Ritter, M. (2006) Understanding and working with 'failed communication' in telecollaborative exchanges. CALICO Journal, 61(2): 623-642.

O'Dowd, R. (2011). Online foreign language interaction: Moving from the periphery to the core of foreign language education? Language Teaching, 44(03), 368-380.

Rubin, J., \& Guth, S. (in press). Collaborative Online International Learning: An Emerging Format for Internationalizing Curricula. Globally Networked Teaching in the Humanities. New York: Routledge.

\title{
Acknowledgements
}

The INTENT survey report and UNICollaboration were funded with support from the European Commission. The report reflects the views only of the authors, and the Commission cannot be held responsible for any use which may be made of the information contained therein.

\footnotetext{
${ }^{1}$ Given the relatively nascent nature of this practice, no single term has yet been identified as the universally accepted term to describe it. The most commonly used names currently are telecollaboration, online intercultural exchange (OIE), virtual exchange, globally-networked learning (GNL), collaborative online international learning (COIL) and Exchange 2.0. In this article we will use telecollaboration and OIE interchangeably but readers should be aware that should they come across these other terms in the literature, they are referring to similar practices.

2 Robert O'Dowd (Project Manager) and Mario Tomé, Universidad de León, Spain; Francois Mangenot and Elke Niessen, Université Stendhal Grenoble, France; Andreas Mueller-Hartmann, Pädagogische Hochschule Heidelberg, Germany; Malgorzata Kurek, Wyzsza Szkola Lingwistyczna, Poland; Francesca Helm and Sarah Guth, Univesità degli Studi di Padova, Italy; Sake Jager and Steve Thorne, Rijksuniversiteit Groningen, Netherlands; Melinda Dooly, Universitat Autònoma de Barcelona, Spain; Mirjam Hauck and Tim Lewis, The Open University, UK. Project number: 517622-LLP-1-2011-ES-ERASMUS-ESMO
}

\begin{abstract}
Authors' biodata
Sarah Guth teaches EFL at the University of Padova, Italy and collaborates with the SUNY COIL Center on professional development programs. Her research lies in the areas of CMC, intercultural communication, and the use of language in telecollaboration. Her current interest is in the normalization of telecollaboration in higher education institutions across disciplines.

Francesca Helm is a researcher and English teacher at the Department of Politics at the University of Padova. Her research interests lie in the areas of intercultural dialogue, telecollaboration, learner identity, new online literacies and English in global communication. She has an MA in TESOL from the Institute of Education, and is currently working on a $\mathrm{PhD}$ at the Universitat Autonoma de Barcelona.

Robert O'Dowd teaches EFL and Applied Linguistics and is Director for International Training at the University of León, Spain. He recently coordinated the European Commission's Project INTENT on integrating telecollaboration in European Higher Education (http://www.scoop.it/t/intent-project-news).

Contact the INTENT project team: intentproject@gmail.com

To join the collaboration platform and find partners and resources for telecollaborative projects: http://uni-collaboration.eu/
\end{abstract}


To cite this article:

Guth, S., Helm, F., \& O’Dowd, R. (2014). Telecollaborative foreign language networks in European universities: A report on current attitudes and practices. Bellaterra Journal of Teaching \& Learning Language \& Literature, 7(4), 1-14. 